\title{
Effect of human chorionic gonadotropin injection before frozen embryo transfer on pregnancy outcomes in endometriosis infertility
}

\section{Yanbo Du}

Reproductive Hospital affiiated to Shandong University

Lei Yan

Reproductive Hospital affiliated to Shandong University

Mei Sun

Reproductive Hospital affiliated to Shandong University

Yan Sheng

Reproductive Hosptial affiliated to Shandong University

\section{Xiufang Li}

Reproductive Hospital affiliated to Shandong University

\section{Zhenhua Feng}

Reproductive Hospital affiliated to Shandong University

Rong Tang ( 13011723415@163.com )

Reproductive Hospital affiliated to Shandong University

\section{Research article}

Keywords: endometriosis, frozen embryo transfer, human chorionic gonadotropin

Posted Date: March 3rd, 2020

DOl: https://doi.org/10.21203/rs.3.rs-15724/v1

License: (c) (i) This work is licensed under a Creative Commons Attribution 4.0 International License. Read Full License 


\section{Abstract}

Purpose To investigate the effect of hCG in hormone replacement regime for frozen thawed embryo transfer in women with endometriosis. Methods We performed a retrospective, database-searched cohort study. The data of endometriosis patients who underwent frozen embryo transfer between 1/1/2009$31 / 8 / 2018$ were collected. According to the protocols for frozen embryo transfer cycle, these patients were divided into two groups: Control group $(n=305)$, and hCG group $(n=362)$. And clinical pregnancy rate, live birth rate, early abortion rate, late abortion rate and ectopic pregnancy rate were compared between the two groups. Results There was a significant increase in clinical pregnancy rate in hCG group (56.6\% vs. $48.2 \%, p=0.035)$ compared to the control group. And the live birth rate in hCG group ( $43.5 \%$ vs. $37.4 \%$, $\mathrm{p}=0.113$ ) also elevated, but the difference is statistically insignificant. Conclusion $\mathrm{hCG}$ administration in hormone replacement regime for FET increase the pregnancy rate in women with endometriosis.

\section{Introduction}

Endometriosis (EM) is a chronic gynecological disease associated with infertility that is characterized by lesion of endometrial-like tissue outside of the uterine cavity [1-2]. Almost half of the women with endometriosis experience infertility [3]. EM affect the outcome of assisted reproductive technology (ART), which compassing a wide sperm of causes, including the poor oocyte, sperm and embryo quality, impaired receptivity of the endometrium and implantation failure [4-5]. Clinically, there can be little doubt that the endometrium of women with endometriosis is less receptive to embryo implantation, and strong evidence exists to suggest that endometrial changes are associated with decreased cycle fecundity as a result of this disease[6]. Endometrial biomarkers are differentially expressed in the endometrium of women with endometriosis compared to normal women [7-8]. Seeking an effective approach to improve endometrial receptivity in endometriosis is a difficult issue in clinical.

Frozen embryo transfer (FET) is recommended for endometriosis in ART. Mohamed suggested that preparation of the endometrium for FET with gonadotropin-releasing-hormone (GnRH) agonists could improve live birth rate in endometriosis, comparing fresh cycles [9]. And recently, Xu found that pregnancy rate, clinical pregnancy rate and birth weight were improved in women with endometriosis who underwent intrauterine injection of human chorionic gonadotropin (hCG) before FET[10]. But these methods are either time-consuming or inconvenient. So we retrospectively analyzed the data of frozen embryo transplantation in patients with endometriosis in an attempt to find a more effective strategy for frozen embryo transplantation.

\section{Materials And Methods}

\section{Subjects}

The retrospective, database-searched cohort study was conducted in Reproductive Hospital Affiliated Shandong University. This study was reviewed and approved by research ethics committee of our 
institution. All patients in the study provided written informed consent for use of their data.

All patients were diagnosed as endometriosis by a laparoscopy, underwent frozen embryo transfer in our hospital during a nine year period (1/1/2009-31/8/2018) were included. Patents older than 42 years at the onset of the cycle, basal FSH $>12 \mathrm{U} / \mathrm{L}$, women with uterine malformation, chromosomal abnormalities, polycystic ovary syndrome, hydrosalpinx, recurrent spontaneous abortion or intrauterine adhesions were all excluded. Finally, 667 women diagnosed with infertility associated with EM were collected. According to whether injection hCG in the protocols for frozen embryo transfer cycle, these patients were divided into two groups : Control group $(n=305)$ and $h C G$ group $(n=362) \square$

\section{Endometrial preparation}

Patients in control group received hormone replacement $(\mathrm{HT})$ regime for frozen embryo transfer. The protocol was started with oral estradiol valerate (Progynova, Delpharm Lille) at a dose of $4 \mathrm{mg}$ to $8 \mathrm{mg}$ per begin on day 2 or 3 of menstrual cycle. Then the thickness of endometrium was measured by transvaginal ultrasound, and the concentrations of estrogen and LH in seurm were measured after about 10 days estradiol valerate treatment. When the endometrial thickness reached at least $7.5 \mathrm{~mm}$, vaginal progestin (Utrogestan; Besins Manufacturing) at dose of $200 \mathrm{mg}$ per day and oral dydrogesterone (Duphaston, Abbott) at dose of $20 \mathrm{mg}$ twice daily was added. When the patients received frozen embryo transfer earlier than 2011, they will be treated with intramuscular injection of progesterone (Progesterone Injection, Zhejiang Xianju Pharmaceutical Co., Ltd) instead. Up to two day 3 cleavage-stage embryos or blastocysts frozen early were thawed and transferred 3 or 5 days, respectively, after the start of progesterone. Women in hCG group received hCG 8000 IU intramuscular injection before progestin administration, and HT regime was the same as control group. Progestin supplementation continued until 12 weeks of pregnancy.

\section{Outcomes}

The primary outcome was clinical pregnancy, which was defined as the detection of an intrauterine gestational sac by transvaginal ultrasoundgraphy after 3 weeks embryo transfer. The second outcome was live birth, which was defined as the delivery of any viable neonate who was 28 weeks of gestation or older. The early abortion rate was defined as the percentage of miscarriage early than 12 weeks in the group. Late abortion rate was the proportion of miscarriage in between 12 and 28 weeks in the group. Preterm birth rate was defined as the percentage of birth before 34 weeks in live birth women. Live birth rate was the proportion of women who birth at least one living child in the group.

\section{Statistical analysis}

Continuous variables were represented as means and standard deviations; differences in variables were compared by means of Student's t-test. Categorical variables were described as frequencies and percentages, with the between-group difference tested by means of the chi-square test and by means of Fisher's exact test when the number of events was less than 5. Two-sides $P$ value of less than 0.05 were considered to indicate statistical significance. 


\section{Results}

\section{Patients}

The baseline characteristics were similar in control group and hCG group (Table 1). There is no difference in the terms of age, $\mathrm{BMI}$, basal endocrine hormone levels, $\mathrm{AMH}$ and the number of oocytes retrieved in fresh cycle between two groups.

Table 1

Basal characteristics of participants

\begin{tabular}{|llll|}
\hline & Control group & HCG group & p value \\
\hline $\mathrm{N}$ & 305 & 362 & \\
\hline $\mathrm{Age}(\mathrm{Years})$ & $31.85 \pm 4.72$ & $31.62 \pm 4.42$ & 0.503 \\
\hline $\mathrm{BMI}\left(\mathrm{kg} / \mathrm{m}^{2}\right)$ & $22.41 \pm 3.96$ & $22.92 \pm 3.33$ & 0.221 \\
\hline $\mathrm{AMH}(\mathrm{ng} / \mathrm{ml})$ & $4.52 \pm 5.66$ & $4.39 \pm 4.16$ & 0.506 \\
\hline $\mathrm{Basal} \mathrm{FSH}(\mathrm{U} / \mathrm{L})$ & $6.70 \pm 2.30$ & $6.56 \pm 1.88$ & 0.380 \\
\hline Basal $\mathrm{LH}(\mathrm{U} / \mathrm{L})$ & $5.81 \pm 3.37$ & $5.75 \pm 3.43$ & 0.813 \\
\hline Basal E2(pg/ml) & $43.50 \pm 33.17$ & $48.40 \pm 43.04$ & 0.453 \\
\hline No. of oocyte retrieved & $14.28 \pm 7.95$ & $13.87 \pm 7.24$ & 0.485 \\
\hline $\begin{array}{l}\text { There were no significant differences between } \mathrm{hCG} \text { group and control group }(\mathrm{P}>0.05) \text { in any of the } \\
\text { baseline characteristics. }\end{array}$ & & \\
\hline
\end{tabular}

\section{Outcomes of FET}

The thickness of endometrium, the stage of transferred embryo and the concentration of E2 in serum did not differ significantly among the two groups. However, FET outcomes were improved in hCG group. The pregnancy rate in hCG group ( $56.6 \%$ vs. $48.2 \%, p=0.035)$ significantly increased, comparing the control group (Table 2). And the live birth rate in hCG group (43.5\% vs. $37.4 \%, p=0.113$ ) also elevated, but the difference is statistically insignificant (Table 2). In addition, there was no significant difference in early abortion rate, late abortion rate, preterm birth rate and ectopic pregnancy rate between control group and hCG group (Table 2). 
Table 2

Outcomes of frozen embryo transfer

\begin{tabular}{|llll|}
\hline & Control group & HCG group & p value \\
\hline Endometrium thickness & $0.93 \pm 0.17$ & $0.92 \pm 0.12$ & 0.236 \\
\hline Transferred embryo stage & & & 0.425 \\
\hline Cleavage stage & $22(7.2 \%)$ & $20(5.5 \%)$ & \\
\hline blastocyte & $283(92.8 \%)$ & $342(94.5 \%)$ & \\
\hline Estrogen & $261.79 \pm 290.85$ & $302.54 \pm 373.58$ & 0.258 \\
\hline LH & $18.36 \pm 11.51$ & $15.11 \pm 13.54$ & $0.029 *$ \\
\hline Pregnancy rate & $48.2 \%$ & $56.6 \%$ & $0.035 *$ \\
\hline Live birth rate & $37.4 \%$ & $43.5 \%$ & 0.113 \\
\hline Preterm birth rate & $4.4 \%$ & $4.3 \%$ & 0.601 \\
\hline Early abortion rate & $9.2 \%$ & $10.8 \%$ & 0.52 \\
\hline Late abortion rate & $0 \%$ & $0.8 \%$ & 0.254 \\
\hline Ectopic pregnancy rate & $1.6 \%$ & $0.3 \%$ & 0.098 \\
\hline *means $\mathrm{p}<0.05, * *$ means $\mathrm{p}<0.001$ & & \\
\hline
\end{tabular}

\section{Discussion}

In our retrospective analysis, we found that the hCG injection could significantly improve pregnancy rate in EM patients undergoing FET. And live birth rate also elevated in hCG group, however, the difference did not reach statically significant.

Several studies have reported that endometriosis affects the endometrium and reduce fertility [11-12]. Reduced implantation, clinical pregnancy rate, ongoing pregnancy and live birth rate was found in women with endometriosis placing sibling oocytes from same donor, comparing women without endometriosis [13]. We also found that higher prevalence of endometrial ployps in infertile patients with endometriosis, implying the special character of eutopic endometrium in endometriosis, which also impair embryo implantation [14].Animal studies support clinical data suggesting that endometriosis leads to implantation defects, again implicating the endometrium. Induction of endometriosis in animals demonstrates similar phenotypes to human disease [15-17]. And gradual and profound alteration in endometrium over time was found in induction of endometriosis in the baboon, involving the inflammation and immune system changes[18]. 
The expression of endometrial biomarkers altered in the eutopic endometrium of endometriosis compared to normal women. Lessey reported that endometrial integrins, which is known as cell-surface receptor for extracellular matrix protein, playing important role in embryo implantation, decreased in women with infertility and endometriosis[19]. Reduced integrin expression also associated with reduced IVF outcomes [20]. Integrin $\beta 5$ could up-regulated under the influence of hCG in stromal cells from endometriotic lesions in vivo [21]. Other key molecules that are required for nomal endometrial receptivity such as HOXA10[22], its expression also reduced in endometriosis, but have been reported to could be induced by hCG[23]. Therefore, hCG injection may improve endometrium receptivity via regulating key molecules related to embryo implantation.

Moreover, endometriosis has been described as a progesterone resistant disease due to the blunted or inadequate response to progesterone of both the eutopic and ectopic endometrial cells and tissue [2427]. This manifested as low expression of progesterone receptor, blunted expression of progesterone target genes [28-30] and inadequate decidualization response[31]. However, the decidualization is an indispensible process for embryo implantation, thus aberrant decidualization would lead to unfavorable effects on embryo implannntation and pregnancy. While it was reported to hCG could regulate progesterone expression via the ERK1/2 pathways [32], and promote human endometrial stromal cell decidulization leading to a significantly stronger induction of decidualization when used in combination with progesterone. [33].

In addatation, it has been well established that the immune system of women with endometriosis is dysfunctional. T regulatory (Treg) cells are altered in endometriosis patients and have been suggested to play a role in pathogenesis of endometriosis and its associated infertility [34]. Lower numbers of Treg cells have been detected in the eutopic endometrium of a non-human primate endometriosis model[18]. And it was reported that hCG-producing trophoblasts could attracted Treg cell [35], and more importantly, hCG was involved in Treg differentiation [36]. Furthermore, aberrant subset of uNK cells was found in the eutopic endometrium of women with endometriosis associated infertility [37]. Immature uNK cells populations exist in infertile women with endometriosis [38]. And hCG has been reported as a regulator of uNK cell proliferation mediating via the mannose receptor (CD206) [39]. These findings may suggest hCG could improve endometrial receptivity via regulating immune cells in eutopic endometrium of infertility women associated with endometriosis.

In our research, the pregnancy rate significantly elevated after hCG injection in endometriosis, however, the difference of live birth rate could not reach statistical significance. This may be the result of insufficient time or dose of hCG, and may improve by replacing single hCG treatments with a repetitive administration scheme [40]. Since our research is retrospective design, the power of conclusion is lower. Further evidence is needed to clarify the protocol that would lead to beneficial outcomes.

\section{Declarations}


Ethics approval and consent to participate: This study was approved by research ethics committee of our institution. All patients in the study have provided written informed consent for use of their data.

Availability of data and materials: The datasets analysed during the current study are not publicly available due to these are all clinical data which needed protect patients identity and privacy, but are available from the corresponding author on reasonable request.

Conflict of Interest: The authors declare that they have no competing interests.

Funding: This study was funded by a grant from the National Nature Science Foundation of China (81571414).

Authors' contributions: All the authors contributed equally to this manuscript. Rong Tang designed the study; Yanbo Du interpreted the data and drafted the article; Lei Yan revised the manuscript critically and accoute for all aspects of the work; Mei Sun and Yan Sheng collected all the data; Xiufang Li and Zhenhua Feng analysis the data.

Acknowledgements: Thanks to other reproductive hospital staff who offered assistance to this study, Qin Gao, Zengxiang Ma, Jingjing Jiang, Hong Liu, Shanshan Gao, Na Yu and Qiaona Yuan.

\section{References}

1. Senapati S, Sammel MD, Morse C, Barnhart KT. Impact of endometriosis on in vitro fertilization outcomes: an evaluation of the Society for Assisted Reproductive Technologies Database. Fertil Steril. 2016;106(1):164-71 e1. doi:S0015-0282(16)61044-0 [pii] 10.1016/j.fertnstert.2016.03.037. 2. Johnson NP, Hummelshoj L. Consensus on current management of endometriosis. Hum Reprod. 2013;28(6):1552-68. doi:det050 [pii] 10.1093/humrep/det050. 3. Meuleman C, Vandenabeele B, Fieuws S, Spiessens C, Timmerman D, D'Hooghe T. High prevalence of endometriosis in infertile women with normal ovulation and normospermic partners. Fertil Steril. 2009;92(1):68-74. doi:S0015-0282(08)00975-8 [pii] 10.1016/j.fertnstert.2008.04.056. 4. Du YB, Gao MZ, Shi Y, Sun ZG, Wang J. Endocrine and inflammatory factors and endometriosis-associated infertility in assisted reproduction techniques. Arch Gynecol Obstet. 2013;287(1):123-30. doi:10.1007/s00404-012-2567-0. 5. Miller JE, Ahn SH, Monsanto SP, Khalaj K, Koti $\mathrm{M}$, Tayade $\mathrm{C}$. Implications of immune dysfunction on endometriosis associated infertility. Oncotarget. 2017;8(4):7138-47. doi:12577 [pii] 10.18632/oncotarget.12577. 6. Lessey BA, Kim JJ. Endometrial receptivity in the eutopic endometrium of women with endometriosis: it is affected, and let me show you why. Fertil Steril. 2017;108(1):19-27. doi:S0015-0282(17)30414-4 [pii] 10.1016/j.fertnstert.2017.05.031. 7. May KE, Villar J, Kirtley S, Kennedy SH, Becker CM. Endometrial alterations in endometriosis: a systematic review of putative biomarkers. Hum Reprod Update. 2011;17(5):637-53. doi:dmr013 [pii] 10.1093/humupd/dmr013. 8. Aghajanova L, Velarde MC, Giudice LC. Altered gene expression profiling in endometrium: evidence for progesterone resistance. Semin Reprod Med. 2010;28(1):51-8. doi:10.1055/s0029-1242994. 9. Mohamed AM, Chouliaras S, Jones CJ, Nardo LG. Live birth rate in fresh and frozen embryo transfer cycles in women with endometriosis. Eur J Obstet Gynecol Reprod Biol. 2011;156(2):177- 
80. doi:S0301-2115(11)00073-X [pii] 10.1016/j.ejogrb.2011.01.020. 10. Xu Z, Chen W, Chen C, Xiao Y, Chen X. Effect of intrauterine injection of human chorionic gonadotropin before frozen-thawed embryo transfer on pregnancy outcomes in women with endometriosis. J Int Med Res. 2019;47(7):2873-80. doi:10.1177/0300060519848928. 11. Kim BG, Yoo JY, Kim TH, Shin JH, Langenheim JF, Ferguson SD et al. Aberrant activation of signal transducer and activator of transcription-3 (STAT3) signaling in endometriosis. Hum Reprod. 2015;30(5):1069-78. doi:dev050 [pii] 10.1093/humrep/dev050. 12. Vannuccini S, Clifton VL, Fraser IS, Taylor HS, Critchley H, Giudice LC et al. Infertility and reproductive disorders: impact of hormonal and inflammatory mechanisms on pregnancy outcome. Hum Reprod Update. 2016;22(1):104-15. doi:dmv044 [pii] 10.1093/humupd/dmv044. 13. Prapas Y, Goudakou M, Matalliotakis I, Kalogeraki A, Matalliotaki C, Panagiotidis Y et al. History of endometriosis may adversely affect the outcome in menopausal recipients of sibling oocytes. Reprod Biomed Online. 2012;25(5):543-8. doi:S1472-6483(12)00469-5 [pii] 10.1016/j.rbmo.2012.07.020. 14. Zhang YN, Zhang YS, Yu Q, Guo ZZ, Ma JL, Yan L. Higher Prevalence of Endometrial Polyps in Infertile Patients with Endometriosis. Gynecol Obstet Invest. 2018;83(6):558-63. doi:000487946 [pii] 10.1159/000487946. 15. Schenken RS, Asch RH. Surgical induction of endometriosis in the rabbit: effects on fertility and concentrations of peritoneal fluid prostaglandins. Fertil Steril. 1980;34(6):581-7. doi:S0015-0282(16)45199-X [pii] 10.1016/s00150282(16)45199-x. 16. Vernon MW. Experimental endometriosis in laboratory animals as a research model. Prog Clin Biol Res. 1990;323:49-60. 17. Hahn DW, Carraher RP, Foldesy RG, McGuire JL. Experimental evidence for failure to implant as a mechanism of infertility associated with endometriosis. Am J Obstet Gynecol. 1986;155(5):1109-13. doi:0002-9378(86)90360-1 [pii] 10.1016/00029378(86)90360-1. 18. Braundmeier A, Jackson K, Hastings J, Koehler J, Nowak R, Fazleabas A. Induction of endometriosis alters the peripheral and endometrial regulatory $\mathrm{T}$ cell population in the non-human primate. Hum Reprod. 2012;27(6):1712-22. doi:des083 [pii] 10.1093/humrep/des083. 19. Lessey BA, Castelbaum AJ, Sawin SW, Buck CA, Schinnar R, Bilker W et al. Aberrant integrin expression in the endometrium of women with endometriosis. J Clin Endocrinol Metab. 1994;79(2):643-9. doi:10.1210/jcem.79.2.7519194. 20. Miller PB, Parnell BA, Bushnell G, Tallman N, Forstein DA, Higdon HL, 3rd et al. Endometrial receptivity defects during IVF cycles with and without letrozole. Hum Reprod. 2012;27(3):881-8. doi:der452 [pii] 10.1093/humrep/der452. 21. Huber A, Hudelist G, Knofler M, Saleh L, Huber JC, Singer CF. Effect of highly purified human chorionic gonadotropin preparations on the gene expression signature of stromal cells derived from endometriotic lesions: potential mechanisms for the therapeutic effect of human chorionic gonadotropin in vivo. Fertil Steril. 2007;88(4 Suppl):1232-9. doi:S0015-0282(07)00342-1 [pii] 10.1016/j.fertnstert.2007.02.006. 22. Du H, Taylor HS. The Role of Hox Genes in Female Reproductive Tract Development, Adult Function, and Fertility. Cold Spring Harb Perspect Med. 2015;6(1):a023002. doi:cshperspect.a023002 [pii] 10.1101/cshperspect.a023002. 23. Fogle RH, Li A, Paulson RJ. Modulation of HOXA10 and other markers of endometrial receptivity by age and human chorionic gonadotropin in an endometrial explant model. Fertil Steril. 2010;93(4):1255-9. doi:S00150282(08)04547-0 [pii] 10.1016/j.fertnstert.2008.11.002. 24. Bulun SE, Cheng YH, Yin P, Imir G, Utsunomiya $\mathrm{H}$, Attar $\mathrm{E}$ et al. Progesterone resistance in endometriosis: link to failure to metabolize estradiol. Mol Cell Endocrinol. 2006;248(1-2):94-103. doi:S0303-7207(05)00444-2 [pii] 10.1016/j.mce.2005.11.041. 25. Yin P, Lin Z, Cheng YH, Marsh EE, Utsunomiya H, Ishikawa H et al. 
Progesterone receptor regulates $\mathrm{Bcl}-2$ gene expression through direct binding to its promoter region in uterine leiomyoma cells. J Clin Endocrinol Metab. 2007;92(11):4459-66. doi:jc.2007-0725 [pii] 10.1210/jc.2007-0725. 26. Yin X, Pavone ME, Lu Z, Wei J, Kim JJ. Increased activation of the PI3K/AKT pathway compromises decidualization of stromal cells from endometriosis. J Clin Endocrinol Metab. 2012;97(1):E35-43. doi:jc.2011-1527 [pii] 10.1210/jc.2011-1527. 27. Wolfler MM, Kuppers M, Rath W, Buck VU, Meinhold-Heerlein I, Classen-Linke I. Altered expression of progesterone receptor isoforms A and B in human eutopic endometrium in endometriosis patients. Ann Anat. 2016;206:1-6. doi:S09409602(16)30036-X [pii] 10.1016/j.aanat.2016.03.004. 28. Attia GR, Zeitoun K, Edwards D, Johns A, Carr BR, Bulun SE. Progesterone receptor isoform A but not $B$ is expressed in endometriosis. $J$ Clin Endocrinol Metab. 2000;85(8):2897-902. doi:10.1210/jcem.85.8.6739. 29. Kao LC, Germeyer A, Tulac S, Lobo S, Yang $\mathrm{JP}$, Taylor RN et al. Expression profiling of endometrium from women with endometriosis reveals candidate genes for disease-based implantation failure and infertility. Endocrinology. 2003;144(7):287081. doi:10.1210/en.2003-0043. 30. Burney RO, Talbi S, Hamilton AE, Vo KC, Nyegaard M, Nezhat CR et al. Gene expression analysis of endometrium reveals progesterone resistance and candidate susceptibility genes in women with endometriosis. Endocrinology. 2007;148(8):3814-26. doi:en.2006-1692 [pii] 10.1210/en.2006-1692. 31. Osteen KG, Bruner-Tran KL, Eisenberg E. Reduced progesterone action during endometrial maturation: a potential risk factor for the development of endometriosis. Fertil Steril. 2005;83(3):529-37. doi:S0015-0282(04)03187-5 [pii] 10.1016/j.fertnstert.2004.11.026. 32. Tapia-Pizarro A, Archiles S, Argandona F, Valencia C, Zavaleta K, Cecilia Johnson M et al. hCG activates Epac-Erk1/2 signaling regulating Progesterone Receptor expression and function in human endometrial stromal cells. Mol Hum Reprod. 2017;23(6):393-405. doi:3068932 [pii] 10.1093/molehr/gax015. 33. Koch Y, Wimberger P, Grummer R. Human chorionic gonadotropin induces decidualization of ectopic human endometrium more effectively than forskolin in an in-vivo endometriosis model. Exp Biol Med (Maywood). 2018;243(11):953-62. doi:10.1177/1535370218782658. 34. Berbic M, Hey-Cunningham AJ, Ng C, Tokushige N, Ganewatta S, Markham R et al. The role of Foxp3+ regulatory T-cells in endometriosis: a potential controlling mechanism for a complex, chronic immunological condition. Hum Reprod. 2010;25(4):900-7. doi:deq020 [pii] 10.1093/humrep/deq020. 35. Schumacher A, Brachwitz N, Sohr S, Engeland $\mathrm{K}$, Langwisch S, Dolaptchieva $\mathrm{M}$ et al. Human chorionic gonadotropin attracts regulatory $\mathrm{T}$ cells into the fetal-maternal interface during early human pregnancy. J Immunol. 2009;182(9):5488-97. doi:182/9/5488 [pii] 10.4049/jimmunol.0803177. 36. Diao LH, Li GG, Zhu YC, Tu WW, Huang CY, Lian RC et al. Human chorionic gonadotropin potentially affects pregnancy outcome in women with recurrent implantation failure by regulating the homing preference of regulatory T cells. Am J Reprod Immunol. 2017;77(3). doi:10.1111/aji.12618. 37. Giuliani E, Parkin KL, Lessey BA, Young SL, Fazleabas AT. Characterization of uterine NK cells in women with infertility or recurrent pregnancy loss and associated endometriosis. Am J Reprod Immunol. 2014;72(3):262-9. doi:10.1111/aji.12259. 38. Thiruchelvam U, Wingfield M, O'Farrelly C. Increased uNK Progenitor Cells in Women With Endometriosis and Infertility are Associated With Low Levels of Endometrial Stem Cell Factor. Am J Reprod Immunol. 2016;75(4):493-502. doi:10.1111/aji.12486. 39. Kane N, Kelly R, Saunders PT, Critchley HO. Proliferation of uterine natural killer cells is induced by human chorionic gonadotropin and mediated via the mannose receptor. Endocrinology. 2009;150(6):2882-8. doi:en.2008-1309 [pii] 10.1210/en.2008-1309. 40. Antonis 
Makrigiannakis TV, Emmanouel Zoumakis,, Jeschke SNKaU. The Role of HCG in Implantation: A MiniReview of Molecular and Clinical Evidence. International Journal of Molecular Sciences. 2017;18(6):1305. 